\title{
Stress testing polymer light-emitting electrochemical cells-suppression of voltage drift and black spot formation
}

\author{
Shiyu Hu and Jun Gao* \\ Department of Physics, Engineering Physics and Astronomy, Queen's University, \\ Kingston, Ontario, K7L 3N6, Canada
}

\begin{abstract}
The stress characteristics of the polymer light-emitting electrochemical cells (PLECs), as measured by luminance decay, voltage drift and black spot formation, have been comprehensively evaluated by varying a host of material and operational parameters. PLECs with the lowest salt concentration of less than $2.5 \%$ exhibit runaway voltage drift that leads to rapid cell destruction. The runaway voltage drift is accompanied by an increasing and exceptionally high luminance level, suggesting an origin dominated by Joule heating that causes the $p-n$ junction to relax into a $p-i-n$ junction. PLECs with the lowest electrolyte polymer concentration and a 5\% salt content exhibit the longest luminance half-life, but are slow to activate and are plagued by black spots. At moderate to high electrolyte concentrations, the PLECs are relatively stable under both forward- and reverse-bias operation, but are not immune to black spots and voltage drift. A T(LVB) lifetime figure-of-merit is introduced to quantitatively account for all three indicators of cell degradation in luminance decay, voltage drift and black spot formation. A surprising discovery is that voltage drift and black spot formation can be effectively suppressed by drastically increasing the electrolyte content. A cell with a
\end{abstract}


$70 \%$ electrolyte content exhibits the best T(LVB) lifetime of nearly 350 hours when operated at a constant current density of $167 \mathrm{~mA} / \mathrm{cm}^{2}$. The black spots can also be effectively eliminated by employing silver instead of aluminum as the cathode material. The results of this study suggest that the preferred junction structure for optimal stability is one with a narrow junction closer to the substrate and a smaller n-doped region relative to the p-doped region. 


\section{Introduction}

Light-emitting electrochemical cells (LECs) are attractive electroluminescent (EL) devices for potential flat-panel display and lighting applications due to their simple, solid-state construction and compatibility with low-cost fabrication processes..$^{[1-11]}$ Compared to organic light-emitting diodes (OLEDs), LECs exhibit a much higher tolerance to variations in electrode work function or active layer thickness, enabling unique device structures such as planar (vs. sandwich) cells with a fully exposed intereletrode gap between identical, inert electrodes. ${ }^{[12]}$ Time-lapsed imaging of planar LECs establishes the fundamental operating mechanism of LECs: in situ electrochemical p- and n-doping of the luminescent semiconductor, followed by light emission in the form of junction EL when the propagating doping fronts make contact to form a $\mathrm{p}-\mathrm{n}$ junction. ${ }^{[13-15]}$ It has been shown that the dynamic doping process involves the entire interelectrode gap, but the LEC junction occupies only a very narrow region between the p- and n-doped neutral regions. ${ }^{[16-18]}$

For practical applications, sandwich LECs are advantageous due to their uniform emission and high efficiencies, although the emitted light must exit via a transparent electrode, and the thickness of active layers becomes important. ${ }^{[19,20]}$ LECs have recently gained some record high efficiencies $(99 \mathrm{~cd} / \mathrm{A})$ even when operated at high luminance levels $\left(>1,900 \mathrm{~cd} / \mathrm{m}^{2}\right) .{ }^{[21]}$ Solution-processed LECs now offer various colors and very high luminance. ${ }^{[22-27]}$ These achievements bring LECs closer to commercial relevance. But one major hurdle still exists in the operational lifetime of these devices. State-of-the-art LECs exhibit operational lifetime of about 1,400-2,000 hours at display brightness (>100 $\mathrm{cd} / \mathrm{m}^{2}$ ) during continuous operation. ${ }^{[28,29]}$ At brightness for lighting applications (a few thousand $\mathrm{cd} / \mathrm{m}^{2}$ ), the lifetime is only about 100 hours. ${ }^{[30]}$ These numbers represent significant improvements over early LECs, but still lag far behind their LED counterparts.

The stress test of LECs is typically carried out with the the application of a constant driving current, during which cell luminance and driving voltage are monitored as a function of time. If the applied constant drive current is significant, a driving voltage far exceeding the minimal turn-on voltage will be initially forced upon the cell, causing rapid cell activation to reach peak luminance. Subsequently, cell luminance decreases and 
a luminance lifetime is determined when cell luminance drops to a percentage (e.g. $50 \%$ ) of the peak luminance. ${ }^{[31]}$

While the luminance half-life is the most quoted figure-of-merit for LEC stability, it does not give a full picture of the LEC degradation process. Some may even argue that the luminance half-life (L50) is not a reliable measure of LEC stability. Recently, polymer LECs (PLECs) were subjected to intermittent testing, during which the devices were allowed to idle for an extended period between successive tests. ${ }^{[32-34]}$ The intermittent test is reminiscent of how a display or lighting panel is operated in the real world, and a key observation was that the lost luminance at the end of the test was largely recoverable when the device was switched on again. This phenomenon is caused by the very doping process itself. The dynamic doping is not only responsible for junction formation and EL, but also causes strong luminescence quenching that degrades the EL. It is the competition of these two aspects, derived from the same dynamic process, that gives rise to an apparent maximum luminance and the luminance decay that follows. Since the doping is partially reversible when the applied drive current is removed, its quenching effect is as well. The dynamic quenching recovery behavior has also been observed in ionic transition metal (iTMC) based LECs. ${ }^{[35]}$

LECs do suffer from permanent degradation and eventual destruction when operated for an extended period and especially under a high stress current, and a better gauge of cell instability is the driving voltage. ${ }^{[34]}$ A decreasing driving voltage is an indication of an on-going doping process that reduces the cell resistivity. The luminance decay that occurs during this period is largely due to quenching and therefore recoverable. Continued testing, however, causes the driving voltage to drift upward (called voltage drift thereafter), signifying an increase in cell resistance that can have a dramatic effect on both cell luminance and cell stability. Indeed, cell destruction is often preceded by a rapidly increasing driving voltage even while the cell luminance is fairly constant or even increasing in magnitude. One extreme example is an LEC that exhibits relatively high, nearly constant luminance (between $451 \mathrm{~cd} / \mathrm{m}^{2}$ and $486 \mathrm{~cd} / \mathrm{m}^{2}$ ) over a period of more than 200 hours, while in fact, during an identical period, the cell was close to failure when the driving voltage increased from $4 \mathrm{~V}$ to $8.7 \mathrm{~V}^{[36]}$ Another indicator of cell degradation is the appearance of non-emissive black spots that reduces the effective 
emitting area of the cell. ${ }^{[33]}$ Their peculiar properties offer important clues as to their origin and possible elimination. ${ }^{[34]}$ This will be further explored in this study.

We believe voltage drift and black spots are the main culprits and indictors of LEC instability, and effective suppression of both is a direct route to truly long-lasting LECs. In this work, we examine voltage drift and black spot formation in archetypical sandwich PLECs that contain a luminescent conjugated polymer (CP), polyethylene oxide (PEO) and a lithium salt (lithium triflate or LiTf). We carried out a comprehensive investigation of their stress characteristics when electrolyte concentration, drive current, bias polarity and cathode metal were varied. We show that all these factors act together to strongly affect the operational and storage stability of PLECs. We assess the operational stability not only in terms of luminance half-life (L), but also in terms of voltage (V) drift and black (B) spot formation. We define a $T(L V B)$ operational lifetime that quantifies all three figures of merit in L, V and B. We discovery that the PLECs become increasingly unstable as the salt content is lowered. Surprisingly, PLECs with extremely high electrolyte loading, up to $70 \%$ by weight, are the most stable among all active layer compositions studied. It is a stunning discovery that both black spot growth and driving voltage drift can be effectively suppressed by increasing the electrolyte loading.

We observe that the PLEC with the lowest salt concentration exhibit the fastest rate of voltage drift. PLECs with the lowest PEO concentration exhibit the longest luminance half-life as a result of slow activation, but are plagued by black spots. At moderate to high electrolyte concentrations, the PLECs are bipolar and relatively stable under both FB and RB operation. At low salt concentration, the symmetry breaks when $\mathrm{RB}$ operation becomes highly unstable due to rapid voltage increase. We propose a simple phenomenological model to explain these experimental observations. Finally, we report PLECs made with a silver cathode that shows excellent shelf stability due to suppressed black spot formation during storage and operation.

\section{Experimental Methods}

The sandwich PLECs used in this study were prepared and tested in an integrated glovebox/evaporator system filled with dry nitrogen $\left(\mathrm{O}_{2}<1 \mathrm{ppm}, \mathrm{H}_{2} \mathrm{O}<1 \mathrm{ppm}\right)$. The conjugated polymer, poly[5-(2'-ethylhexyloxy)-2-methoxy-1,4-phenylene vinylene] $\left(\mathrm{MEH}-\mathrm{PPV}, \mathrm{M}_{\mathrm{n}}=3.3 \times 10^{5} \mathrm{~g} / \mathrm{mol}\right)$, was obtained from OLEDKing Optoelectronic 
Mateirals, China. Poly(ethylene oxide) (PEO, $\mathrm{M}_{\mathrm{n}}=4 \times 10^{5} \mathrm{~g} / \mathrm{mol}$ ), and lithiumtrifluoromethanesulfonate (LiTf), were purchased from Sigma Aldrich and used as received. The cyclohexanone solutions of MEH-PPV, PEO and LiTf were prepared separately. Suitable amounts of the solutions were mixed to create casting solutions with the desired weight ratios of the active materials. The casting solutions were stirred on a magnetic hotplate at room temperature for at least 5 hours prior to use. The indium tin oxide (ITO) coated glass substrates $\left(1.5 \times 1.5 \mathrm{~cm}^{2}\right)$ were cleaned in three ultrasonic baths that contained a detergent, acetone and isopropanol, respectively. The casting solution was spun cast onto the ITO glass substrates and dried at $50{ }^{\circ} \mathrm{C}$ for 5 hours to remove any residual solvent. The polymer-covered ITO glass substrates were then annealed at $130{ }^{\circ} \mathrm{C}$ for $30 \mathrm{~min}$, followed by quick cooling to room temperature by placing them onto a big copper block. The thickness of the resulting polymer films was around $300 \mathrm{~nm}$, as measured by a DektakXT stylus profiler. Aluminum of $100 \mathrm{~nm}$ or silver of $60 \mathrm{~nm}$ in thickness was thermally evaporated onto the polymer films through shadow mask to create devices with an active area of $2 \times 3 \mathrm{~mm}^{2}$.

The devices were tested inside a black box fitted with a calibrated photodiode. A LabVIEW controlled Keithley 238 source measurement unit was used to supply a constant test current ranging from $1 \mathrm{~mA}$ to $10 \mathrm{~mA}$. For a constant $5 \mathrm{~mA}$ test current, the current density was therefore $83 \mathrm{~mA} / \mathrm{cm}^{2}$. The EL and PL images were captured using a Nikon D610 camera fitted with a macrolens through the glove box window. When taking PL images, the constant current was removed and a UV lamp was positioned below the PLECs for illumination. The EL images were captured using the same camera settings(1/50 s, f/5.6, ISO 400). For the PL images an ISO sensitivity of 1600 was used.

\section{Results}

The archetypical PLECs of this study contain three components, each serving a critical function in the operation of these devices. MEH-PPV is a luminescent CP widely used in both PLEDs and PLECs due to its excellent solubility, redox stability and film forming ability. PEO is a solid polyether solvent of lithium salt. LiTf, once dissolved in PEO, provides the mobile cations and anions necessary for doping. The composition of PLEC is of utmost significance in determining its characteristics and should be carefully 
considered in any study. Here, we investigate the effects of active layer composition on all three indicators of PLEC decay-luminance decay, voltage drift and black spot growth. We also compare the stress characteristics of the PLECs with respect to bias polarity and current density. The comprehensive study uncovers a wealth of information about the PLEC degradation process. The film composition was varied systematically, by changing the amount of one component at a time while keeping the other two components fixed. The results are shown below in sub-sections entitled on the parameters changed.

\section{a. Salt concentration}

At a fixed 1:1 weight ratio between MEH-PPV and PEO, the salt content was varied. Figure 1 shows the stress curves of cells with a 1:1:0.1 composition. The tests were conducted on four identical cells fabricated on the same substrate. The applied test currents are indicated in the individual graphs along with some extracted luminance and driving voltage values. The four-panel composite graph compares the effects of test current magnitude (left vs. right) and bias polarity (top vs. bottom). Figure 1 (a) shows the time dependent luminance and driving voltage under a constant applied forward bias (FB) current of $+5 \mathrm{~mA}$. The PLEC exhibit very fast response, reaching maximum luminance within seconds. This was followed by a rapid decrease in both luminance and driving voltage. The luminance decay during the initial half hour or so was mainly caused by the effect of quenching. Subsequently, cell luminance continued to decrease while the driving voltage remained low $(<2.7 \mathrm{~V})$ and nearly constant for the reminder of the test. 
(a)

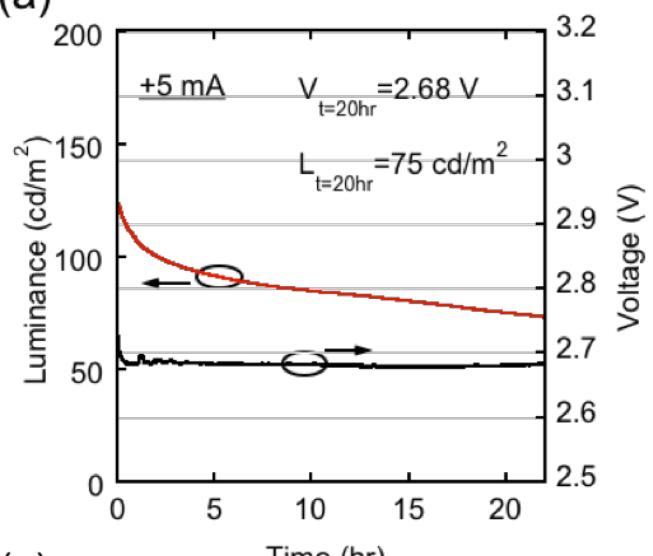

(c)

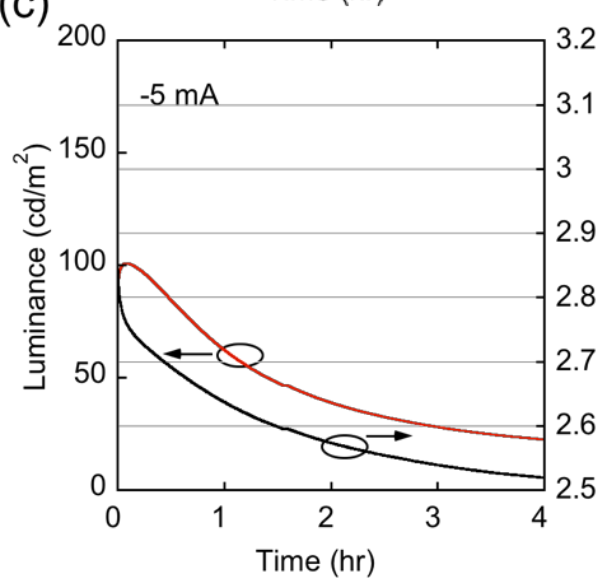

(b)

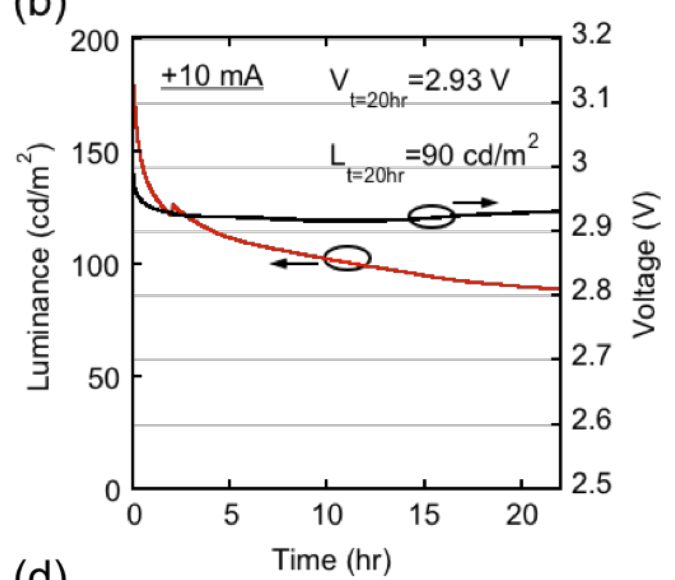

(d)

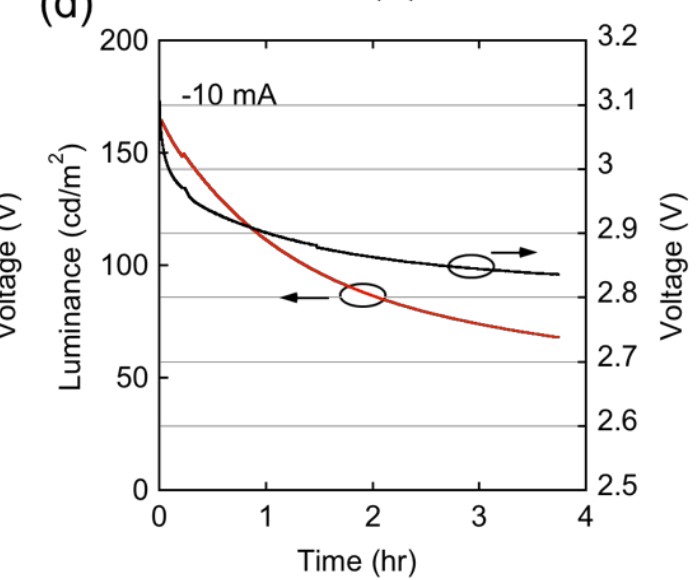

Figure 1. Constant-current tests of identical PLECs with a structure and composition of ITO/MEHPPV:PEO:LiTf(1:1:0.1)/Al. The numbers in parenthesis indicate the weight ratios of the three active layer components. The test currents and bias polarities are indicated in the graphs. A "+" sign indicates the ITO electrode is biased positive relative to the aluminum electrode, and vice versa. $\mathrm{V}_{\mathrm{t}=20 \mathrm{hr}}$ indicates the driving voltage applied at $\mathrm{t}=20$ hours after the test current was applied, and $\mathrm{L}_{\mathrm{t}=20 \mathrm{hr}}$ indicates the cell luminance at the same time. Note a $5 \mathrm{~mA}$ test current corresponds to a current density of $83 \mathrm{~mA} / \mathrm{cm}^{2}$ in this study. At $\mathrm{t}=20 \mathrm{hr}$, the efficiencies of cells (a) and (b) are $0.09 \mathrm{~cd} / \mathrm{A}$ and $0.05 \mathrm{~cd} / \mathrm{A}$, respectively.

Figure 1 (b) shows the PLEC stress curves with the FB current doubled to +10 $\mathrm{mA}$. As expected, both luminance and the driving voltage increased. A rapid, initial decrease is again observed in both luminance and driving voltage. A slight voltage drift is observed after about 15 hours of continuous operation.

When the bias polarity is reversed, as shown in Figure 1(c) and 1(d), the cells exhibit comparable peak luminance and driving voltage as in FB tests. The RB tests, however, show a much faster luminance decay that led to a much short luminance half- 
life of only 2-3 hours. The faster luminance decay is accompanied by a faster rate of voltage decrease. This again points to the effect of doping and quenching as the main cause of the apparent luminance decay. The tests were terminated when cell luminance dropped to below $50 \%$ of the peak luminance (about 4 hours). No voltage drift was observed during this period.

Next, the salt concentration was halved to arrive at a 1:1:0.05 active layer composition. As shown in Figure S1 of Supporting Information, the cells exhibit nearly identical luminance and very similar general behaviors to those shown in Figure 1. The driving voltage at $\mathrm{t}=20$ hours increased slightly to $2.77 \mathrm{~V}$ and $3.06 \mathrm{~V}$ for the $+5 \mathrm{~mA}$ and $+10 \mathrm{~mA}$ tests, respectively. For both FB tests, voltage drift is observed in the second half of the tests. The results in Figure 1 and Figure S1 suggest the the salt concentrations in these cells are sufficiently high to promote fast doping and the formation of a lightemitting junction. These cells are "bipolar" in exhibiting similar luminance and driving voltage under both FB and RB operations. The original PLECs, with a 1:1:0.2 composition, exhibit the most recognizable "bipolar" behavior with nearly symmetric cell current and luminance when the bias voltage is scanned from -4 to $+4 \mathrm{~V}^{[12]}$ The bipolar behavior is a hallmark of LECs, signifying charge injection and transport processes dominated by doping rather than by the injection barriers at the electrode interfaces.

In Figure 2, the salt concentration is further halved, resulting in a 1:1:0.025 composition. The FB tests at $+5 \mathrm{~mA}$ and $+10 \mathrm{~mA}$ remain very similar to those of Figure 1, except for a more pronounced voltage drift that started early. The RB tests, however, are entirely different. The cells became far more luminous, reaching peak luminance of $400 \mathrm{~cd} / \mathrm{m}^{2}$ and $1000 \mathrm{~cd} / \mathrm{m}^{2}$, respectively. But the cells quickly failed due to rapid voltage drift that caused the driving voltage to reach the set compliance value of $100 \mathrm{~V}$. At a $2.5 \%$ salt concentration, the RB operation is no longer viable due to voltage instability. Moreover, the fast voltage drift was observed from the beginning of the tests and accompanied by a large and fast increase in luminance. 
(a)

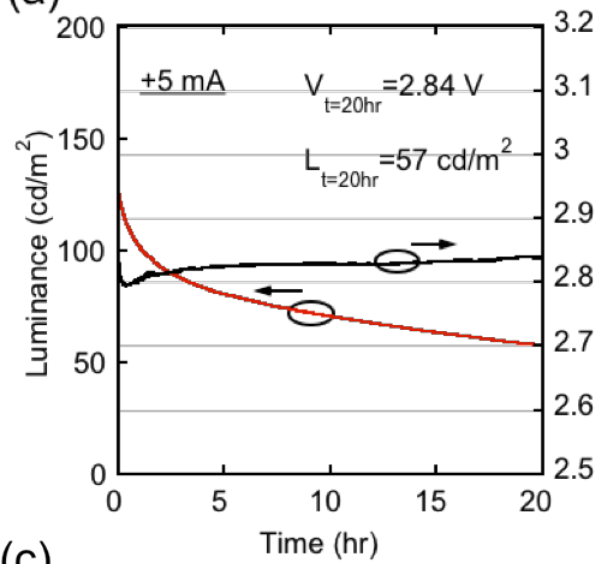

(c)

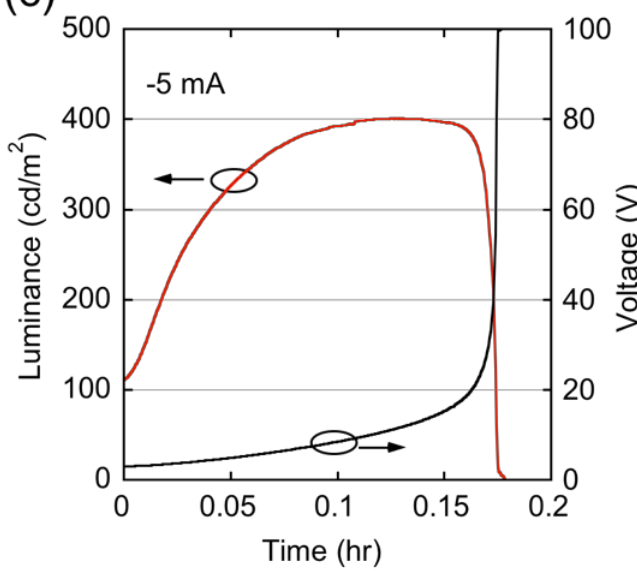

(b)

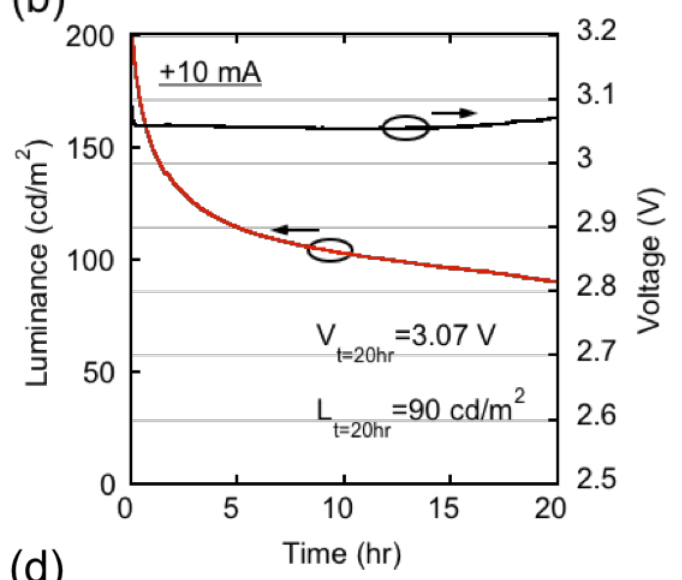

(d)

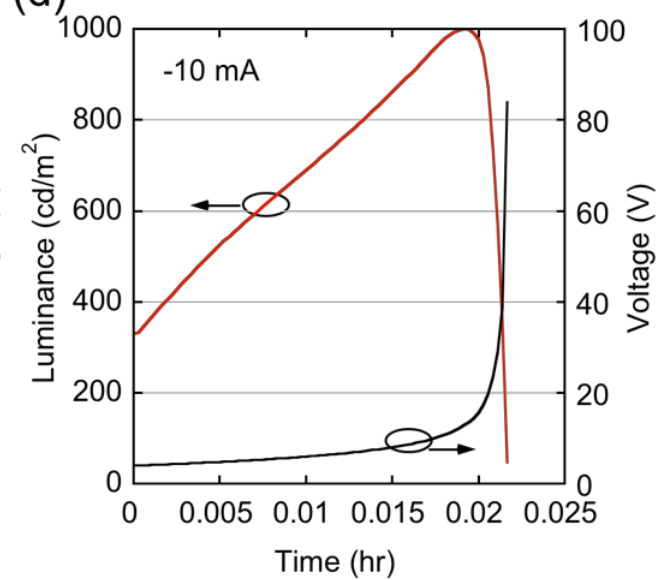

Figure 2. Constant-current stress tests of identical PLECs with a composition of MEHPPV:PEO:LiTf=1:1:0.025 (weight ratio). The test currents and bias polarities are indicated in the graphs. At $\mathrm{t}=20 \mathrm{hr}$, the efficiencies of cells (a) and (b) are $0.07 \mathrm{~cd} / \mathrm{A}$ and $0.05 \mathrm{~cd} / \mathrm{A}$, respectively.

In Figure 3, the cells had the lowest salt concentration of $1 \%$ in the present study. To our knowledge, the $1 \%$ salt concentration is also the lowest among all PLECs ever reported. The cells were no longer stable even under $+5 \mathrm{~mA}$ or $+10 \mathrm{~mA}$, as shown in Figure 3(a) and Figure 3(b). Once again, cell instability manifests as high luminance and a rapidly increasing driving voltage. The driving voltage reached close to $10 \mathrm{~V}$ in minutes. The cells could not be activated to operated under $-5 \mathrm{~mA}$ and $-10 \mathrm{~mA}$. Instead, Figure 3(c) shows a test at $+1 \mathrm{~mA}$. The cell exhibits "normal behavior" and showed no sign of catastrophic failure during the $\sim 20$-hour test period. Figure 3(d) shows a test 
under $-1 \mathrm{~mA}$. The cell was unstable despite emitting at a similar luminance as the cell under $+1 \mathrm{~mA}$.

(a)

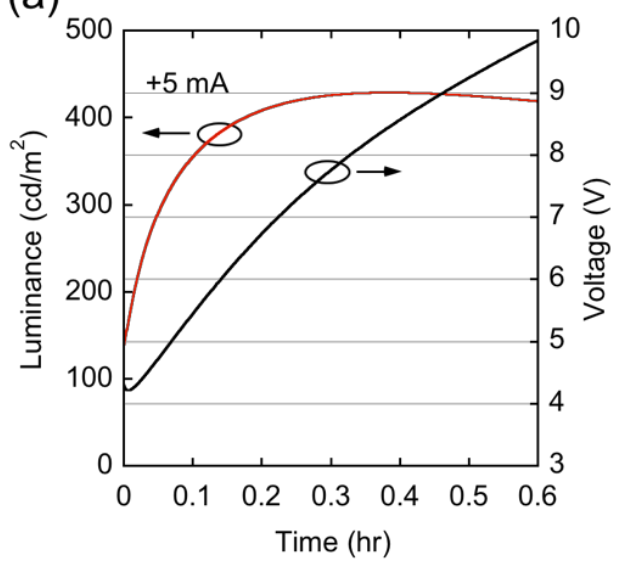

(c)

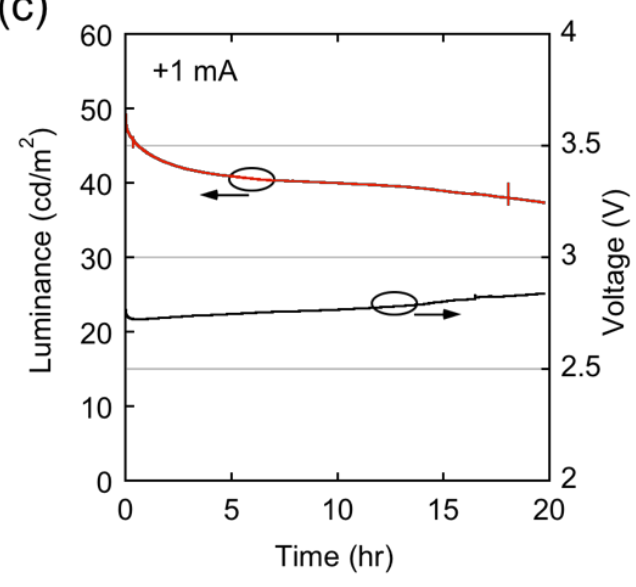

(b)

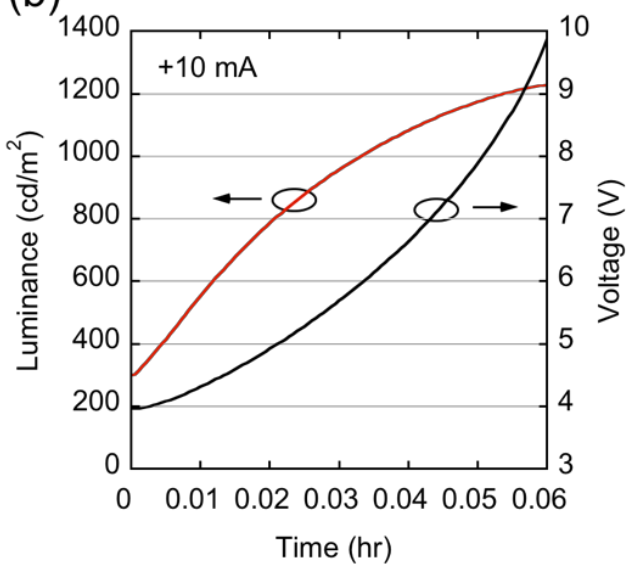

(d)

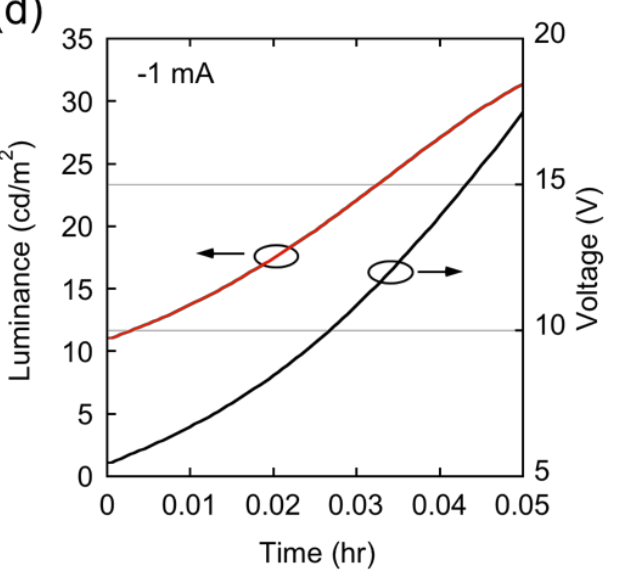

Figure 3. Constant-current stress tests of identical PLECs with a composition of MEHPPV:PEO:LiTf=1:1:0.01 (weight ratio). The test currents and bias polarities are indicated in the graphs. Note the lower panels (c) and (d) compare tests at $+1 \mathrm{~mA}$ and $-1 \mathrm{~mA}$, not $-5 \mathrm{~mA}$ and $-10 \mathrm{~mA}$. The efficiency of cell (a) is $0.52 \mathrm{~cd} / \mathrm{A}$ at $431 \mathrm{~cd} / \mathrm{m}^{2}$. The efficiency of cell (b) is $0.74 \mathrm{~cd} / \mathrm{A}$ at $1234 \mathrm{~cd} / \mathrm{m}^{2}$.

The above tests reveal dramatic effects of salt concentration on the stress behaviors of PLECs. As the salt concentration is reduced, the PLECs progressively become unstable, as characterized by an accelerated voltage drift that led to an unsustainably high driving voltage. This occurred first under RB operation. At the lowest salt concentration, the PLEC is highly unstable except under a small FB current. 


\section{b. PEO concentration}

At a fixed MEH-PPV and LiTf weight ratio of 1:0.05, the PEO content was varied. Figure 4 shows the FB tests for two compositions: 1:0.5:0.05 and 1:0.2:0.05. Compared to the 1:1:0.05 cells shown in Figure S1, these two compositions exhibit very similar behaviors. The luminance decay rate, however, is slightly lower and the driving voltage did not show appreciable upward drift.

In Figure 5, the PEO concentration is further reduced to 0.1 and a continuous test was carried out for more than 500 hours. The composition of 1:0.1:0.05 is very close to an optimized cell that exhibits the longest operational lifetime for MEH-PPV LECs. ${ }^{[37]}$ Indeed, the cell sustained a luminance of higher than $100 \mathrm{~cd} / \mathrm{m}^{2}$ for more than 400 hours. But it took nearly 90 hours for the cell to reach $100 \mathrm{~cd} / \mathrm{m}^{2}$. One solution to speed up the cell activation was to apply a large "pre-bias" for a short period, followed by a lower stress current. ${ }^{[37]}$ In addition to an extremely slow turn-on response, the cell had poor emission uniformity, as shown by the images. In the beginning, the cell emitted as isolated bright spots. Later, large black spots occupied a significant portion of the cell surface. 
(a)
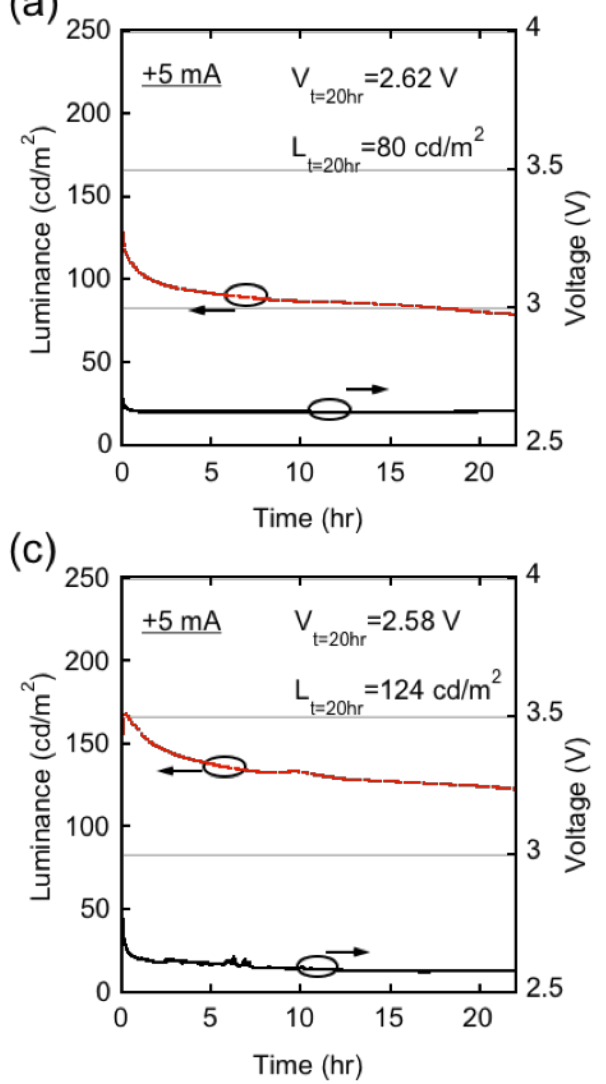

(b)

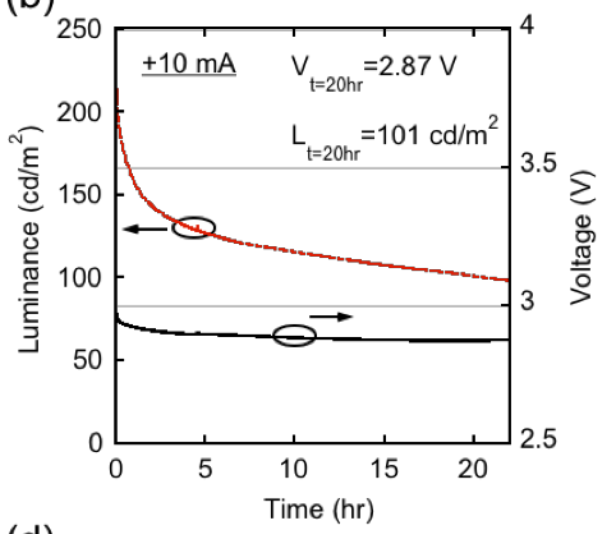

(d)

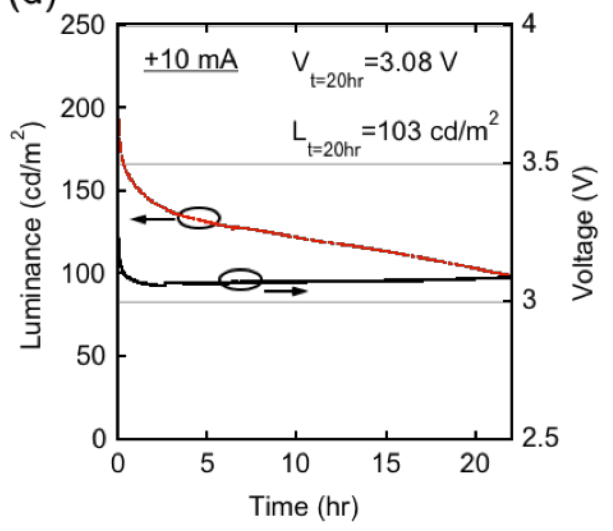

Figure 4. Constant-current stress tests of identical PLECs with two different compositions. (a) and (b) are for identical cells with a composition of MEH-PPV:PEO:LiTf=1:0.5:0.05. (c) and (d) are for identical cells with a composition of MEH-PPV:PEO:LiTf=1:0.2:0.05. At $\mathrm{t}=20 \mathrm{hr}$, the efficiencies of cells (a)-(d) are 0.1 $\mathrm{cd} / \mathrm{A}, 0.06 \mathrm{~cd} / \mathrm{A}, 0.15 \mathrm{~cd} / \mathrm{A}$ and $0.06 \mathrm{~cd} / \mathrm{A}$, respectively. 


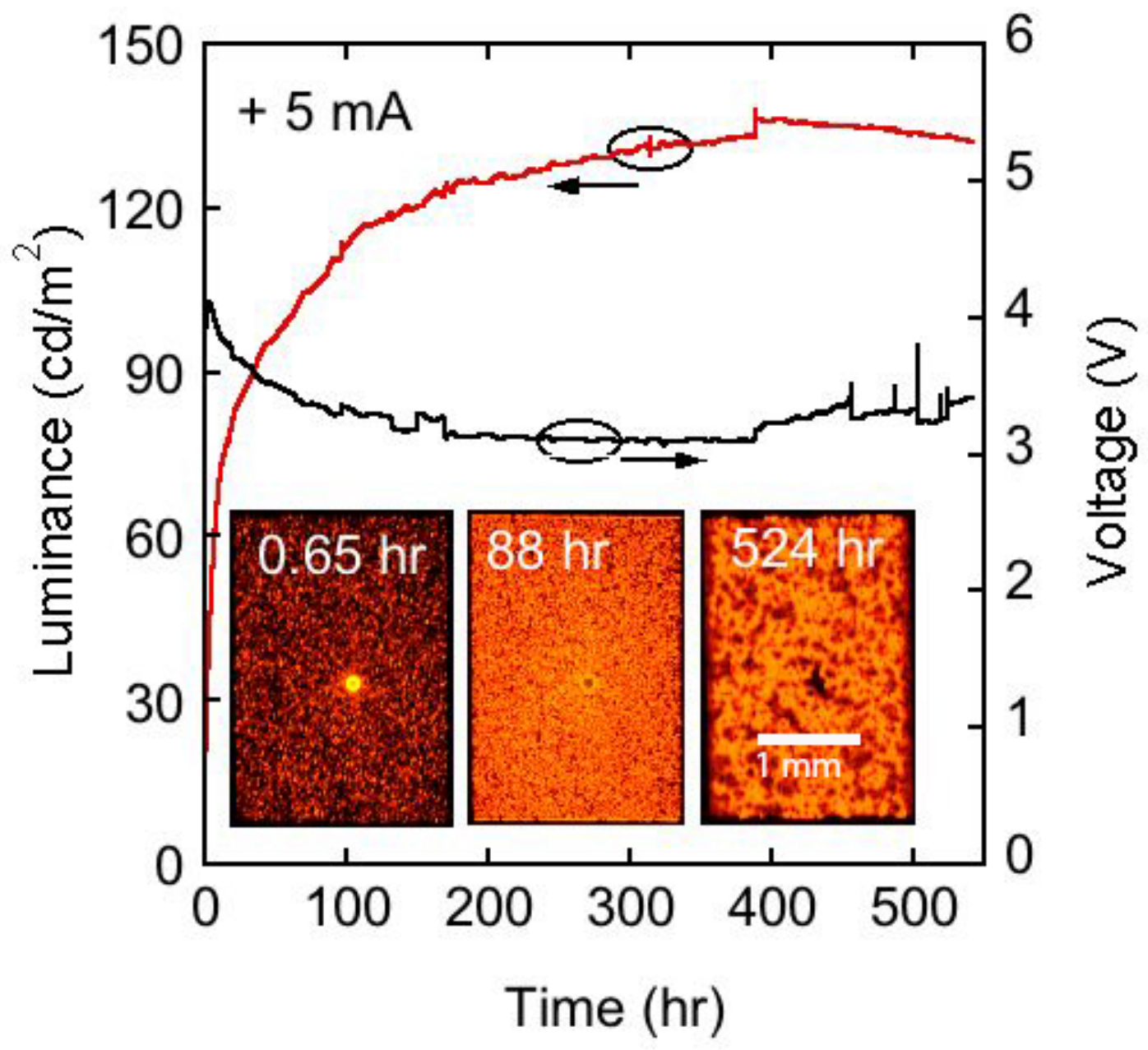

Figure 5. Constant-current stress tests a PLEC with a composition of MEH-PPV:PEO:LiTf=1:0.1:0.05 (weight ratio). The test current was $+5 \mathrm{~mA}$. The images are taken in the dark during the tests. The time when the image was taken is indicated in the pictures. The efficiency of the cell is $0.17 \mathrm{~cd} / \mathrm{A}$ at peak luminance of $143 \mathrm{~cd} / \mathrm{m}^{2}$. The active area of the cell is $2 \mathrm{~mm}(\mathrm{~W})$ by $3 \mathrm{~mm}(\mathrm{H})$.

In fact, significant black spot formation has been observed in all 28 cells with the seven compositions described above. Figure S2 shows the black spots of four example cells with different compositions. For each cell, EL images were taken at the beginning and end of test. Also included is a PL image of the respective cell right after the bias current was removed, showing significant PL quenching and black spots that correspond to the ones observed in the EL images. In both the current and previous studies, we 
observe the black spot growth is characterized by an increase in size rather than the number of black spots. This behavior is shown in Figure 6 for a 1:0.2:0.05 cell tested under $+5 \mathrm{~mA}$. While only $3.6 \%$ of the cell surface was populated by black spots at $\mathrm{t}=1.1$ hrs, the coverage increased to $28 \%$ after 93 hours of continuous operation as the black spots progressively became bigger. Figure S3 provides a detailed explanation on how the black spot coverage is calculated.

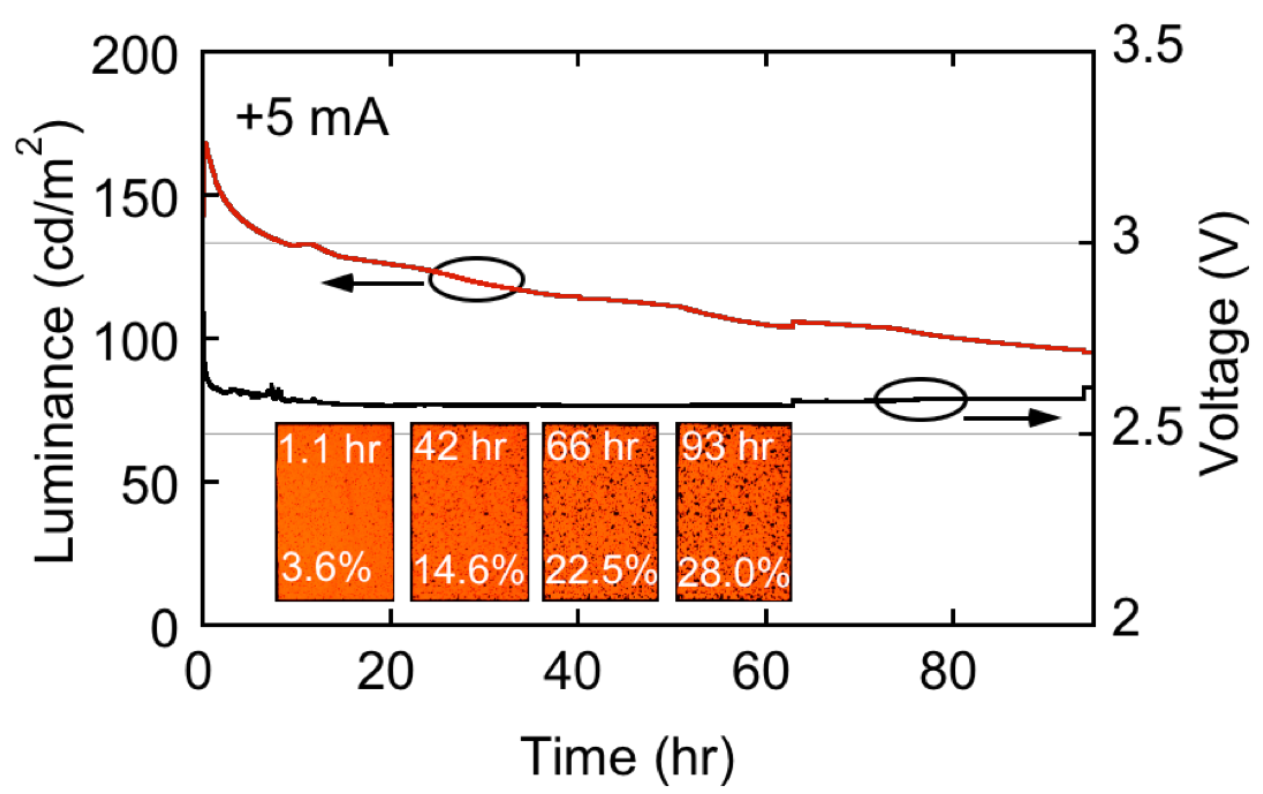

Figure 6. Constant-current stress tests of a PLEC with a composition of MEH-PPV:PEO:LiTf=1:0.2:0.05 (weight ratio). The test current was $+5 \mathrm{~mA}$. The images are taken in the dark during the tests. The time when the image was taken as well as the black spot coverage are shown in the pictures. At $\mathrm{t}=93 \mathrm{hr}$, the efficiency of the cell was $0.12 \mathrm{~cd} / \mathrm{A}$ at $96 \mathrm{~cd} / \mathrm{m}^{2}$. The active area of the cell is $2 \mathrm{~mm}(\mathrm{~W})$ by $3 \mathrm{~mm}(\mathrm{H})$.

\section{c. MEH-PPV concentration}

The tests in sections $\boldsymbol{a}$ and $\boldsymbol{b}$ show that driving voltage drift and black spots are prevalent in these PLECs. The detrimental voltage drift has a very strong correlation with salt concentration. For cells with less than 5\% salt content, rapid voltage drift leads cell destruction that can occur in minutes. These observations led us to go in the opposite direction by significantly increasing the salt content relative to MEH-PPV. The PEO to LiTf ratio was fixed at 5:1 to ensure the salt is adequately solvated. This is equivalent to reducing the MEH-PPV content relative to that of the electrolyte. Figure 7 shows the +5 $\mathrm{mA}$ test of a 0.5:1:0.2 cell. Due to the high electrolyte content, the cell turned on instantly 
and exhibited uniform emission. Amazingly, the cell did not show significant black spot formation throughout the continuous, 95 -hour test. The largest black spot coverage was calculated at only $1 \%$. Moreover, the driving voltage remained constant and the luminance decreased by only about $23 \%$. Note the small driving voltage jump at $\mathrm{t}=70$ hours is an artifact caused by the opening of the test box lid for picture taking. We note that the peak luminance is only $87 \mathrm{~cd} / \mathrm{m}^{2}$. This is likely due to the fact that the film contains less than $30 \%$ luminescent CP. But it is remarkable that cell still gave off uniform emission. Figure 8 shows an identical cell that underwent a continuous test at $+10 \mathrm{~mA}$ for 438 hours. The combination of high test current and long test duration did cause significant development of black spots, but not nearly as severe as in cells with a lower electrolyte content. More important, the cell voltage exhibit excellent stability and only reached $3.67 \mathrm{~V}$ at the end of test.

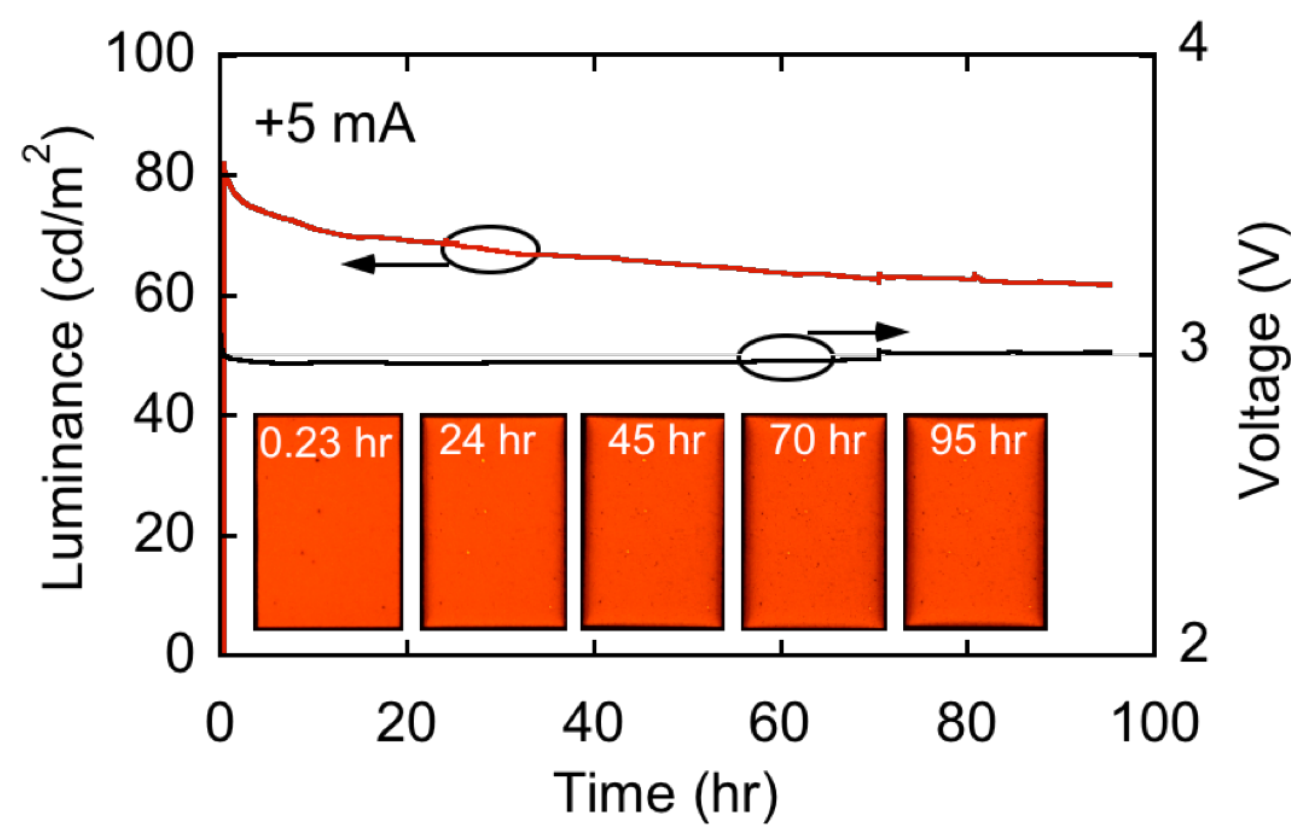

Figure 7. Constant-current stress tests of a PLEC of the composition ITO/MEH-PPV:PEO:LiTf=0.5:1:0.2 (weight ratio)/Al. The test current was $+5 \mathrm{~mA}$. The images are taken in the dark during the tests. The time when the image was taken is shown in the pictures. At $t=95 \mathrm{hr}$, the efficiency of the cell was $0.07 \mathrm{~cd} / \mathrm{A}$ at 62 $\mathrm{cd} / \mathrm{m}^{2}$. The active area of the cell is $2 \mathrm{~mm}(\mathrm{~W})$ by $3 \mathrm{~mm}(\mathrm{H})$. 


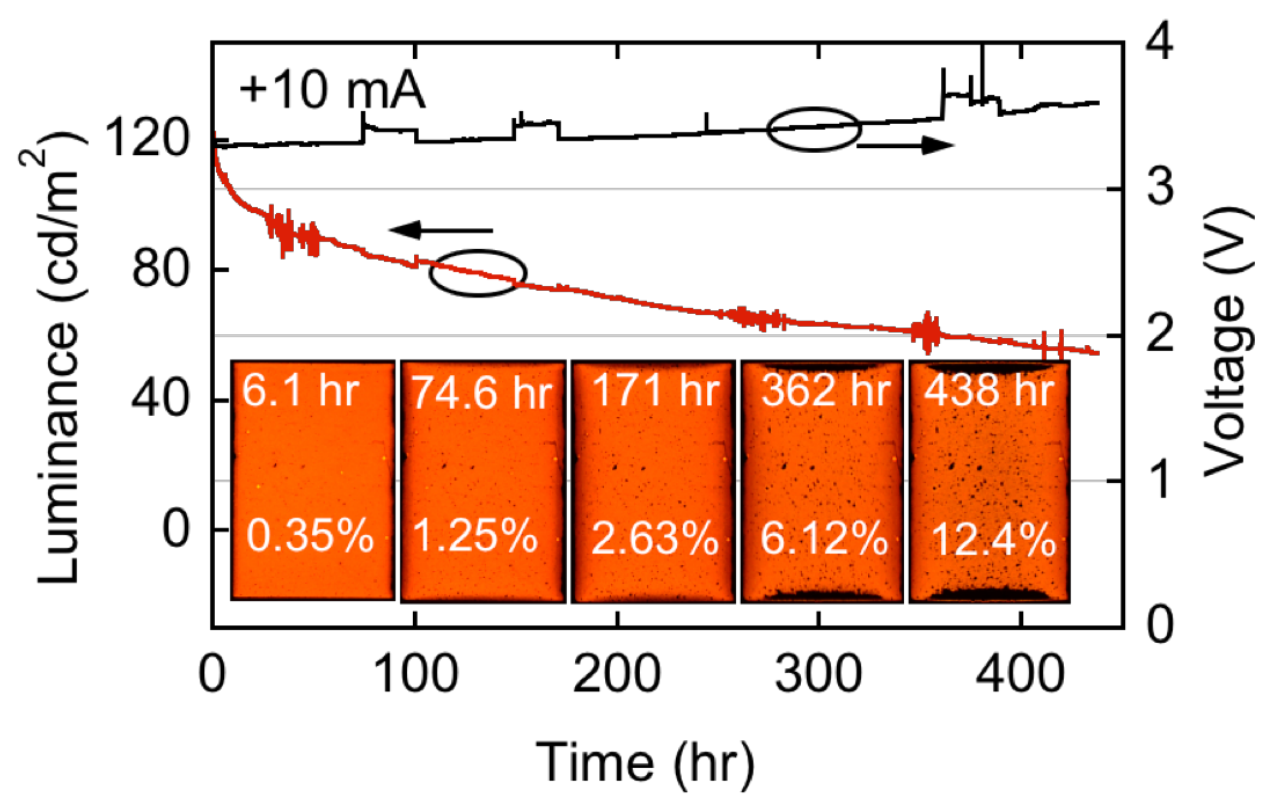

Figure 8. Constant-current stress tests of identical PLECs of the composition ITO/MEHPPV:PEO:LiTf=0.5:1:0.2 (weight ratio)/Al. The test current was $+10 \mathrm{~mA}$. The images are taken in the dark during the tests. The time when the image was taken as well as the black spot coverage are shown in the pictures. At $\mathrm{t}=350 \mathrm{hr}$, the efficiency of the cell was $0.037 \mathrm{~cd} / \mathrm{A}$ at $61 \mathrm{~cd} / \mathrm{m}^{2}$. The active area of the cell is 2 $\mathrm{mm}(\mathrm{W})$ by $3 \mathrm{~mm}(\mathrm{H})$.

Cells were also made with an even higher electrolyte content. The 0.25:1:0.2 cells behaved similarly to the 0.5:1:0.2 cells shown above but with an even lower luminance. The driving voltage never exceeded $4 \mathrm{~V}$, even after more than 200 hours operated at +10 mA. With a composition of $0.17: 1: 0.2$, the cell exhibited much reduced luminance (a few $\mathrm{cd} / \mathrm{m}^{2}$ ) and sudden destruction when the driving voltage increased sharply after about 13 hours of testing at $+5 \mathrm{~mA}$ (about 70 hours at $+1 \mathrm{~mA}$ ). Another key observation is that even with a high electrolyte content, significant black spot growth has been observed in cells that were stored for an extended period (e.g. 120 days).

\section{d. Ag cathode}

All cells shown in the previous sections had an aluminum cathode. Previous studies strongly suggest that it is the localized chemical interaction between the $\mathrm{Al}$ cathode and the LEC active layer that seeded the initial appearance of black spots. ${ }^{[3,34]}$ Extended storage of a cell after the deposition of Al electrodes always led to the significant development of large black spots even when the cell was operated for the first 
time. By contrast, cells made with aged polymer films, but freshly deposited Al electrodes were free of black spots. For comparison, we fabricated a cell with a silver cathode and composition of MEH-PPV:PEO:LiTf=1:0.5:0.05, as shown below.

(a)

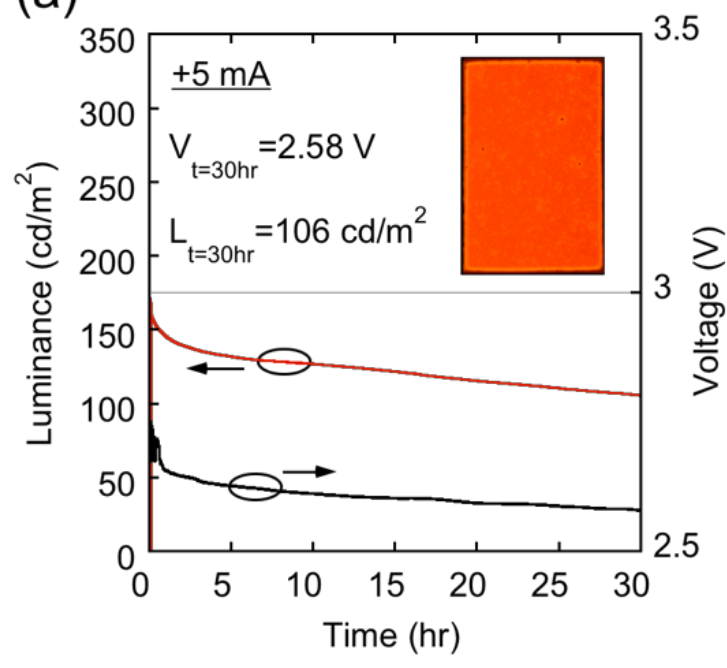

(b)

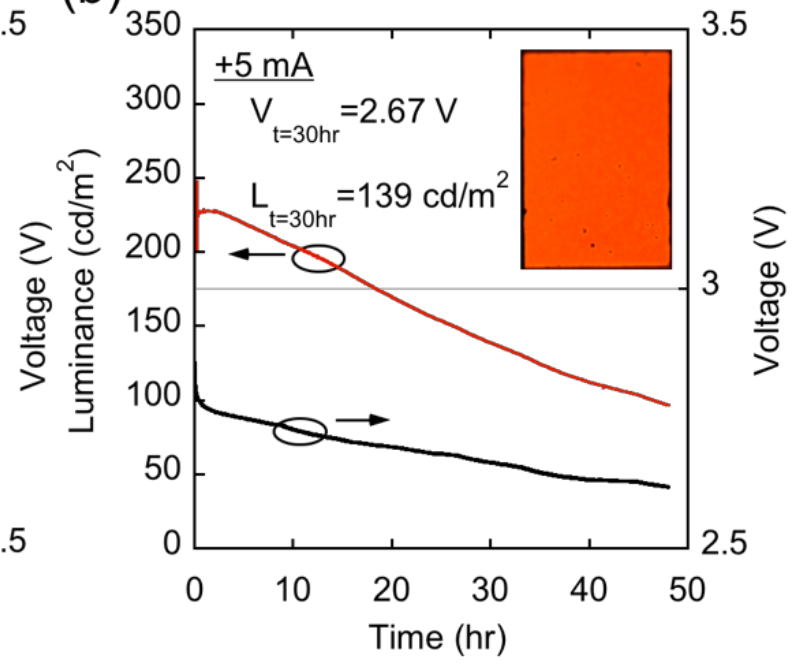

Figure 9. Constant-current stress tests of identical PLECs of the composition of ITO/MEHPPV:PEO:LiTf/Ag=1:0.5:0.05 (weight ratio). The test currents and bias polarities are indicated in the graphs. At $\mathrm{t}=30 \mathrm{hr}$, the efficiencies of cells (a) and (b) are $0.13 \mathrm{~cd} / \mathrm{A}$ and $0.17 \mathrm{~cd} / \mathrm{A}$, respectively. The active area of the cell is $2 \mathrm{~mm}(\mathrm{~W})$ by $3 \mathrm{~mm}(\mathrm{H})$.

Figure 9 shows the $+5 \mathrm{~mA}$ tests of two identical devices. Figure 9(a) shows a test immediately after the deposition of the Ag cathode. The cell exhibits very similar luminance vs. time and driving voltage vs. time characteristics to an Al cell of the same active layer composition (Figure 4). Black spots, however, did not develop by the end of test at 31 hours. A second device on the same substrate was tested for the first time after being stored for 90 days, as shown in Figure 9(b). Amazingly, the emission remained largely free of black spots except for a few near the middle and bottom sections of the cell. The storage also led to a significantly higher peak luminance, a phenomenon also observed in a cell underwent intermittent testing with long delays.

\section{Discussion}

The results presented in the previous sections show that the stress characteristics of PLECs are strongly affected by a myriad of factors, with the chief among them being 
the active layer composition. By studying cells with a salt content ranging from $1 \%$ to $40 \%$ (weight ratio relative to MEM-PPV), we observe vastly different behaviors with respect to cell stability. The results demonstrate that the operational stability of PLECs can not be assessed on luminance alone. Voltage drift and black spots are prevalent and main indicators of cell degradation. This is especially true for cells with a low electrolyte content. Unexpectedly, cells with an extremely high salt and PEO content displayed the best overall stability with minimum black spot development, slow voltage drift and excellent luminance half-life even under high driving current. To have a more stringent measure of the operational stability of these PLECs, we introduce a T(LVB) lifetime, which is defined as the minimum of three quantities: luminance half-life (L50), time for the driving voltage to reach $4 \mathrm{~V}$ (V4) and time for black spots to develop and cover $5 \%$ of cell surface (B5). That is: $\mathrm{T}(\mathrm{LVB})=\mathrm{Min}(\mathrm{L} 50, \mathrm{~V} 4, \mathrm{~B} 5)$. The luminance half-life is a commonly used figure-of-merit for luminance stability. The $5 \%$ black spot coverage is a requirement to ensure that the emission is largely uniform. For these PEO-based PLECs, the electrochemical stability window is typically limited to less than $4 \mathrm{~V}$. In this study, the rapid voltage drift quickly destroyed the cells when the driving voltage reached over $4 \mathrm{~V}$, as shown in Figure 2 and Figure 3. We stress that the T(LVB) lifetime can be defined differently for a different material system and under different testing conditions. Some iTMC-based LECs, for example, exhibit a highly stable average driving voltage under pulsed current operation. ${ }^{[29,38-42]}$ The purpose of introducing this new figure of merit is to quantitatively account for the contribution of voltage drift and black spots to the operational stability of LECs. Among the PLECs tested, the 0.5:1:0.2 cell exhibits the longest $\mathrm{T}(\mathrm{LVB})$ lifetime of $\sim 350$ hours at $+10 \mathrm{~mA}\left(167 \mathrm{~mA} / \mathrm{cm}^{2}\right)$.

In PPV-based PLEDs, voltage drift is recognized as an equal indicator of device degradation as luminance decay. In a study by Silvestre et al., both voltage drift and light degradation are assigned a common origin due to trap formation in the bulk of the polymer film. ${ }^{[43]}$ In a study by Parker et al. on PPV PLEDs, the voltage drift is shown to be thermally activated and linearly proportionally to the charges passed. ${ }^{[44]}$ This latter relation means the greater the driving current, the faster the voltage drift, a phenomenon also observed in these PLECs. More important, Parker's study shows that the voltage drift is entirely caused by the passage of electrons via the tests of electron-only and hole- 
only devices. In PPV-based PLECs, the behavior of voltage drift is much more complicated due to the presence of an electrolyte. Some key observations are: (i) "normal" or gradual voltage drift occurs while the cell luminance decreases. (ii) runaway voltage drift is accompanied by a very high and fast-increasing luminance level. (iii) voltage drift accelerates when the salt content is reduced. The PEO content, at a fixed salt concentration of $5 \%$, has less effect on voltage drift. (iv) run-away voltage drift can occur under both FB and RB operations.

Clearly, the voltage drift in PLECs is affected by the salt or ion concentration. In planar PLECs, it has been shown that a high salt concentration is necessary to sustain doping propagation and to form a light-emitting $\mathrm{p}$-n junction at a fixed driving voltage. ${ }^{[45]}$ In extremely large planar PLECs, high PEO and salt contents are universally employed to achieve cell activation and light emission. ${ }^{[46]}$ Numerical simulation shows that the steady state current density increases linearly with ion (salt) concentration. ${ }^{[47]}$ In sandwich PLECs, the effect of salt concentration was studied by Fang et al. ${ }^{[37]}$ For cells operated under a fixed bias of $3 \mathrm{~V}$, the authors report that the salt concentration had a limited effect on the power efficiency of the cells, but did not explicitly show the time-dependent cell current. The authors further studied the effect of PEO concentration, and arrived at an optimized MEH-PPV:PEO:KTf composition of 1:0.085:0.03. A cell with such a composition exhibited an impressive luminance half-life of about 850 hours under $1 \mathrm{~mA}$ constant current operation, but required a PEDOT-PSS hole-injection layer and a higher pre-bias current for fast activation. The test also showed a driving voltage that approached $4 \mathrm{~V}$ at the end of the 1,000 hour-test as a result of voltage drift. In smallmolecule or ionic-transition metal (ITMC) LECs, added lithium salt has been shown to improve the response and luminance of the cells. ${ }^{[48,49]}$ These studies all point to the importance of salt concentration in LEC operation. However, they do not directly discuss the origin of voltage drift in LECs and nor can they account for the above observations stated in (i)-(iv).

We first take note of the observation (ii) as stated above. How do we reconcile the seemingly contradictive observations of simultaneously increasing driving voltage and luminance level? What causes the cell luminance to increase to such a high level? This peculiar behavior is unique to LECs. Indeed, the same behavior has been observed in 
planar PLECs stressed under a constant current. ${ }^{[50]}$ In Al/MEH-PPV:PEO:LiTf/Al planar PLECs, run-away voltage drift is accompanied by significant luminance increase that is accelerated by an increase in test temperature $(250 \mathrm{~K}-300 \mathrm{~K})$. At cryogenic temperatures (200K-220K), the voltage drift was gradual during a test duration of more than 100 hours. However, even at $200 \mathrm{~K}$, the voltage drift is strongly affected by the substrate on which the device is fabricated. The substrate was in contact with the cold finger of the cryostat. A cell made on a sapphire substrate showed minimal voltage drift and no luminance increase, while an identical device made on a glass substrate showed much faster voltage drift and significant luminance increase. Therefore, we can confidently conclude that the root cause of runaway voltage drift and luminance increase is a thermal one. At high cell temperature, the light-emitting p-n junction is no longer stable despite being held under an increasing bias voltage. The effect of heating, either external or internal, causes the light-emitting $\mathrm{p}$-n junction to relax into a p-i-n junction with a less quenched, quasiintrinsic emission zone. At the same time, cell resistance increases due to the formation and growth of the less doped " $i$ " region. Such a p-i-n junction can be intentionally formed by relaxing an as-formed p-n junction through thermal cycling, resulting in an increase in luminance by 4 to 26 -fold. ${ }^{[51]}$ Direct imaging confirmed the p-i-n junction structure. Intentional formation of a p-i-n junction has also been demonstrated in a sandwich PLEC, which resulted in a $100 \%$ increase in luminance with only a $10 \%$ increase in driving voltage. At a fixed driving current, a run-away voltage drift eventually causes cell destruction by Joule heating. ${ }^{[52]}$ Thermal instability is also consistent with the observation that run-away voltage drift and cell destruction occur at a much faster rate at a higher stress current, as shown in Figures $2 \& 3$. The small $6 \mathrm{~mm}^{2}$ sandwich cell was dissipating nearly $100 \mathrm{~mW}$ of electrical power while emitting at $1,000 \mathrm{~cd} / \mathrm{m}^{2}$ just before failure, as shown in Figure 2 (d).

We caution that the input electric power and its heating effect alone cannot explain all the experimental observations of this study with respect to voltage drift. For example, the cell shown in Figure 3(d), operated at $-1 \mathrm{~mA}$, had an initial input electric power well below that of cells operated under higher currents. Yet the cell was unstable and exhibited behavior (ii) right from the beginning. The same cell (with $1 \%$ salt), on the other hand, exhibited good stability and normal (slow) voltage drift operated under +1 
$\mathrm{mA}$. We believe junction relaxation is still the main cause of behavior (ii) shown in Figure 3(d), but other factors are also at play. Clearly, whether behavior (i) or (ii) occurs is also dependent on salt concentration and bias polarity. These dependences suggest the structure of the LEC junction is also an important factor.

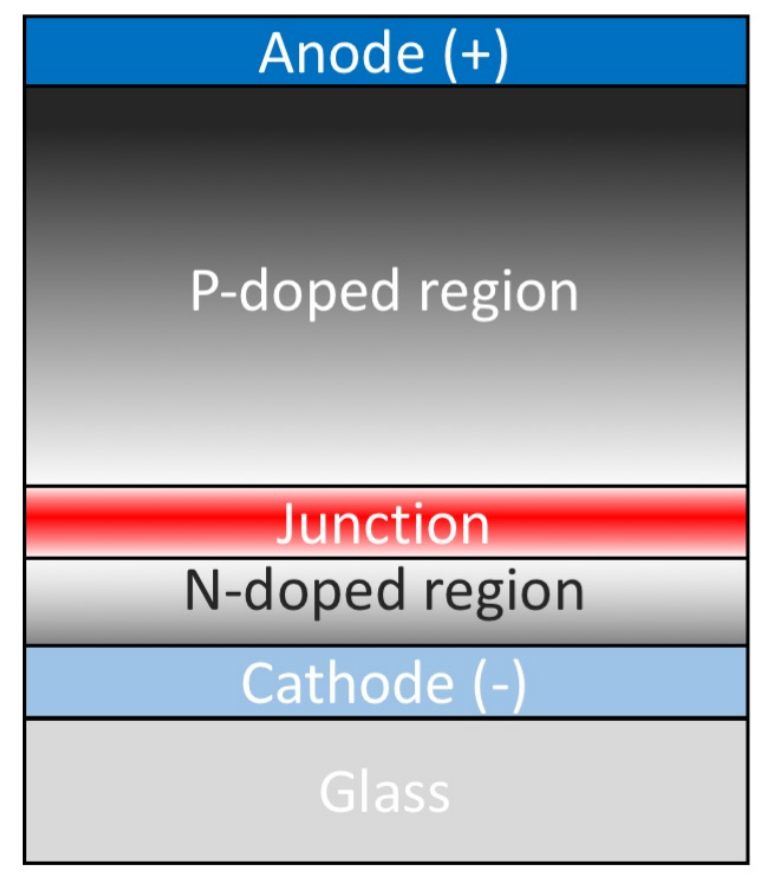

(a) Stable configuration

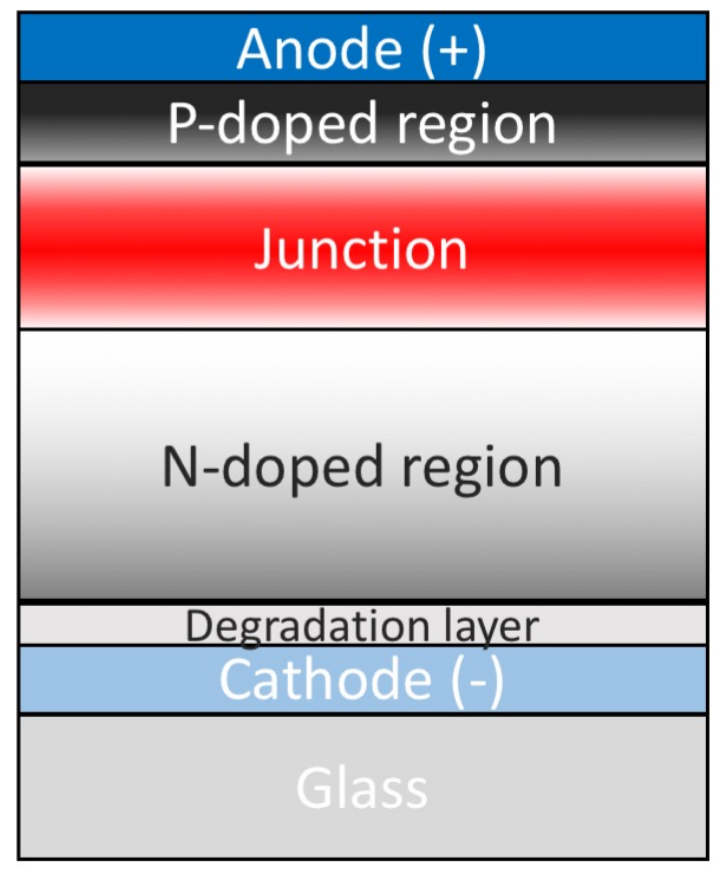

(b) Unstable configuration

Figure 10. Idealized LEC junction structures. (a) a stable junction configuration less affected by the adverse effect of joule heating and irreversible reactions involving electrode, n-doped region or the electrolyte. (b) a highly unstable configuration showing a widened junction and n-doped region. A degradation layer is included to account for all irreversible reactions involving the active layer components and the cathode. The doped regions are shown with gradient to reflect a graded doping profile.

Indeed, an activated LEC is not a simple, homogenous resistor but rather a complicated junction formed in a mixed conductor. The activated LEC consists of neural $\mathrm{p}$ - and $\mathrm{n}$-doped regions separated by a junction or space charge region. The $\mathrm{p}$ - and $\mathrm{n}$ doped regions differ greatly in PL and conductivity. ${ }^{[53]}$ The $\mathrm{p}$ - and n-doped regions have the opposite majority charge carriers and counterions. As a result, an activated LEC can be regarded as an "electron-only" conductor and a "hole-only" conductor connected in series. Based on Parker's observations in PPV-based PLEDs, it is reasonable to believe 
that an LEC with a larger n-doped region should exhibit a higher driving voltage and a faster voltage drift. In addition, the position of the p-n junction is also important. Exciton quenching is expected if the junction is located too close to the metal electrode, and a junction formed closer to the cathode should be more susceptible to self-heating due to its larger separation from the substrate. It is believed that self-heating in PLECs occurs mainly in the junction region. ${ }^{[54]}$

Based on these discussions, we present Figure 10 to summarize our understanding of PLEC operational stability. For stable operation, it is desired that the emitting junction be closer to the substrate to facilitate heat dissipation by conduction via the glass substrate in the absence of any forced convection. The junction width as well as the width of the more resistive $\mathrm{n}$-doped region should be small to minimize driving voltage and voltage drift. The favored configuration is therefore an inverted cell, as shown in Figure 10(a). By contrast, Figure 10(b) depicts a cell that is unstable. A "degradation" layer is added to account for the experimental observation of such a layer due to electrochemical "side-reactions' at the cathode interface. ${ }^{[55]}$ We believe that a high $(>4 \mathrm{~V})$ and increasing driving voltage is associated with not only junction relaxation, which explains the luminance increase, but also irreversible chemical changes that can occur at the cathode interface, in the n-doped region and at the junction. When the latter is the dominant cause, the runaway voltage drift is not accompanied by any luminance increase. ${ }^{\left[{ }^{[5]}\right.}$ In this study, the fastest voltage drift (for the same applied current) was observed in PLECs with the lowest salt content and operated under RB. They likely have a junction structure similar to that shown in Figure 10(b).

To realize the preferred junction structure shown in Figure 10(a), a transparent conductive film based on silver nanowires could be used as the cathode material to replace $\mathrm{Al} .^{[56,57]} \mathrm{A}$ silver cathode may also prevent the formation of black spots, as demonstrated in Figure 9. A high work function metal such as gold or silver could be evaporated on top of the polymer film to serve as the anode. Better heat management is also important in order to prevent overheating of the cell during operation. This could be realized with pulsed operation and/or effective heat sinking of the cell. To ensure the light-emitting junction is formed closer to the substrate, the electrolyte salt should be carefully chosen. In extremely large planar PLECs based on MEH-PPV and PEO, a 
lithium salt gives rise to the narrowest n-doped region. ${ }^{[58]}$ The impact of salt on cell stability needs to be re-evaluated for thin sandwich cells operated at a much lower bias voltage and for cells with a high electrolyte content.

\section{Conclusions}

We performed a comprehensive study of PLECs that contained a luminescent polymer, an electrolyte polymer and a lithium salt. The stress characteristics of the PLECs, as measured by luminance decay, voltage drift and black spot formation, were evaluated by varying a host of material and operational parameters. We observe that the PLEC with the lowest salt concentration, when operated under RB, exhibits the fastest voltage drift, leading to rapid cell destruction. The PLEC with the lowest PEO concentration and a 5\% salt content exhibits the longest luminance half-life, but is slow to activate and plagued by black spots. At moderate to high electrolyte concentrations, the PLECs are relatively stable under both FB and RB operation, but are not immune to black spots and voltage drift. We demonstrated two methods for the effective suppression of black spots by employing an active layer with extremely high electrolyte or by using $\mathrm{Ag}$ as the cathode. We propose a new T(LVB) lifetime figure-of-merit to better assess the stress stability of PLECs by considering luminance decay, voltage drift and black spot coverage. A cell with a 70\% electrolyte content exhibits the best T(LVB) lifetime. Since the run-away voltage drift is always accompanied by high luminance, we explain its origin as junction relaxation caused by joule heating. The results of this study suggest a preferred junction structure for optimal stability is one with a narrow junction closer to the substrate and a smaller n-doped junction relative to the $\mathrm{p}$-doped region.

\section{Corresponding Author}

* Prof. Jun Gao

Email: jungao@queensu.ca

\section{Acknowledgement}

The study at Queen's University was supported by the Natural Sciences and Engineering Research Council of Canada (NSERC), grant number RGPIN-2015-05344. 


\section{References}

[1] Z. Shu, F. Kemper, E. Beckert, R. Eberhardt, A. Tunnermann, Materials TodayProceedings 2017, 4, 5039.

[2] K. Sato, S. Uchida, S. Toriyama, S. Nishimura, K. Oyaizu, H. Nishide, Y.

Nishikitani, Advanced Materials Technologies 2017, 2.

[3] T. Sakanoue, F. Yonekawa, K. Albrecht, K. Yamamoto, T. Takenobu, Chemistry of Materials 2017, 29, 6122.

[4] Z. Shu, O. Pabst, E. Beckert, R. Eberhardt, A. Tunnermann, in Organic Photonic Materials and Devices Xviii, Vol. 9745 (Eds: C. E. Tabor, F. Kajzar, T. Kaino, Y. Koike), 2016.

[5] A. Sandstrom, L. Edman, Energy Technology 2015, 3, 329.

[6] J. Frohleiks, F. Wefers, S. Wepfer, A. R. Hong, H. S. Jang, E. Nannen, Advanced Materials Technologies 2017, 2.

[7] E. Fresta, R. D. Costa, Journal of Materials Chemistry C 2017, 5, 5643.

[8] J. Zimmermann, N. Jurgensen, A. J. Morfa, B. H. Wang, S. Tekoglu, G.

Hernandez-Sosa, Acs Sustainable Chemistry \& Engineering 2016, 4, 7050.

[9] E. M. Lindh, A. Sandstrom, M. R. Andersson, L. Edman, Light-Science \& Applications 2016, 5.

[10] E. M. Lindh, A. Sandstrom, L. Edman, Small 2014, 10, 4148.

[11] F. C. Chen, Y. Yang, Q. Pei, Applied Physics Letters 2002, 81, 4278.

[12] Q. B. Pei, G. Yu, C. Zhang, Y. Yang, A. J. Heeger, Science 1995, 269, 1086.

[13] J. Gao, J. Dane, Applied Physics Letters 2004, 84, 2778.

[14] S. Tang, W.-Y. Tan, X.-H. Zhu, L. Edman, Chemical Communications 2013, 49, 4926.

[15] S. B. Meier, S. van Reenen, B. Lefevre, D. Hartmann, H. J. Bolink, A. Winnacker, W. Sarfert, M. Kemerink, Advanced Functional Materials 2013, 23, 3531.

[16] M. J. Jafari, J. Liu, I. Engquist, T. Ederth, Acs Applied Materials \& Interfaces 2017, 9, 2747.

[17] F. AlTal, J. Gao, Journal of Applied Physics 2016, 120, 115501.

[18] F. AlTal, J. Gao, Phys. Status Solidi RRL 2015, 9, 77.

[19] X. Li, J. Gao, G. Liu, Organic Electronics 2013, 14, 1441.

[20] E. M. Lindh, P. Lundberg, T. Lanz, J. Mindemark, L. Edman, Scientific Reports 2018, 8 .

[21] S. Tang, A. Sandstrom, P. Lundberg, T. Lanz, C. Larsen, S. van Reenen, M. Kemerink, L. Edman, Nat. Commun. 2017, 8.

[22] J. Liu, J. Oliva, K. Tong, F. C. Zhao, D. Chen, Q. B. Pei, Scientific Reports 2017 , 7.

[23] Y. Xiong, L. Li, J. J. Liang, H. Gao, S. Y. Chou, Q. B. Pei, Materials Horizons $2015,2,338$.

[24] S. Tang, P. Murto, X. F. Xu, C. Larsen, E. G. Wang, L. Edman, Chemistry of Materials 2017, 29, 7750.

[25] A. K. Pal, D. B. Cordes, A. M. Z. Slawin, C. Momblona, A. Pertegas, E. Orti, H. J. Bolink, E. Zysman-Colman, Rsc Advances 2017, 7, 31833. 
[26] C. D. Ertl, C. Momblona, A. Pertegas, J. M. Junquera-Hernandez, M. G. La-Placa, A. Prescimone, E. Orti, C. E. Housecroft, E. C. Constable, H. J. Bolink, Journal of the American Chemical Society 2017, 139, 3237.

[27] M. Di Marcantonio, J. E. Namanga, V. Smetana, N. Gerlitzki, F. Vollkommer, A. V. Mudring, G. Bacher, E. Nannen, Journal of Materials Chemistry C 2017, 5, 12062.

[28] J. Mindemark, S. Tang, J. Wang, N. Kaihovirta, D. Brandell, L. Edman, Chemistry of Materials 2016, 28, 2618.

[29] H. J. Bolink, E. Coronado, R. D. Costa, E. Orti, M. Sessolo, S. Graber, K. Doyle, M. Neuburger, C. E. Housecroft, E. C. Constable, Advanced Materials 2008, 20, 3910.

[30] Z. Yu, M. Wang, G. Lei, J. Liu, L. Li, Q. Pei, Journal of Physical Chemistry Letters 2011, 2, 367.

[31] J. Gao, Chempluschem 2018, 83, 183.

[32] X. Li, J. Gao, G. Liu, Applied Physics Letters 2013, 102, 223303.

[33] X. Li, F. AlTal, G. Liu, J. Gao, Applied Physics Letters 2013, 103, 243304.

[34] F. AlTal, J. Gao, Organic Electronics 2015, 18, 1.

[35] S. B. Meier, D. Hartmann, D. Tordera, H. J. Bolink, A. Winnacker, W. Sarfert, Physical Chemistry Chemical Physics 2012, 14, 10886.

[36] J. Gao, F. AlTal, Applied Physics Letters 2014, 104, 143301.

[37] J. Fang, P. Matyba, L. Edman, Advanced Functional Materials 2009, 19, 2671.

[38] M. Martinez-Alonso, J. Cerda, C. Momblona, A. Pertegas, J. M. Junquera-

Hernandez, A. Heras, A. M. Rodriguez, G. Espino, H. Bolink, E. Orti, Inorganic Chemistry 2017, 56, 10298.

[39] J. E. Namanga, N. Gerlitzki, A. V. Mudring, Advanced Functional Materials 2017, 27.

[40] J. E. Namanga, N. Gerlitzki, B. Mallick, A. V. Mudring, Journal of Materials Chemistry C 2017, 5, 3049.

[41] D. Tordera, S. Meier, M. Lenes, R. D. Costa, E. Orti, W. Sarfert, H. J. Bolink, Advanced Materials 2012, 24, 897.

[42] R. D. Costa, E. Orti, H. J. Bolink, S. Graber, C. E. Housecroft, E. C. Constable, Advanced Functional Materials 2010, 20, 1511.

[43] G. C. M. Silvestre, M. T. Johnson, A. Giraldo, J. M. Shannon, Applied Physics Letters 2001, 78, 1619.

[44] I. D. Parker, Y. Cao, C. Y. Yang, Journal of Applied Physics 1999, 85, 2441.

[45] J. F. Fang, Y. L. Yang, L. Edman, Applied Physics Letters 2008, 93.

[46] J. Gao, J. Dane, Applied Physics Letters 2003, 83, 3027.

[47] S. van Reenen, P. Matyba, A. Dzwilewski, R. A. J. Janssen, L. Edman, M.

Kemerink, Advanced Functional Materials 2011, 21, 1795.

[48] Y. Shen, D. D. Kuddes, C. A. Naquin, T. W. Hesterberg, C. Kusmierz, B. J. Holliday, J. D. Slinker, Applied Physics Letters 2013, 102.

[49] K. Y. Lin, L. D. Bastatas, K. J. Suhr, M. D. Moore, B. J. Holliday, M. MinaryJolandan, J. D. Slinker, Acs Applied Materials \& Interfaces 2016, 8, 16776.

[50] Y. Zhang, J. Gao, Journal of Applied Physics 2006, 100, 084501.

[51] Y. G. Zhang, Y. F. Hu, J. Gao, Applied Physics Letters 2006, 88, 163507.

[52] J. H. Jang, L. H. Kim, Y. J. Jeong, K. Kim, T. K. An, S. H. Kim, C. E. Park, Organic Electronics 2016, 34, 50.

[53] Y. Hu, J. Gao, Journal of the American Chemical Society 2011, 133, 2227. 
[54] T. Wagberg, P. R. Hania, N. D. Robinson, J.-H. Shin, P. Matyba, L. Edman, Advanced Materials 2008, 20, 1744.

[55] J. Fang, P. Matyba, N. D. Robinson, L. Edman, Journal of the American Chemical Society $2008,130,4562$.

[56] Y. Lee, M. Suh, K. Kim, H. Kim, D. Kim, H. Chang, D. Lee, Y. Kim, S. W. Kim, D. Y. Jeon, Organic Electronics 2017, 43, 64.

[57] L. Li, Z. B. Yu, W. L. Hu, C. H. Chang, Q. Chen, Q. B. Pei, Advanced Materials 2011, 23, 5563.

[58] Y. Hu, J. Gao, Applied Physics Letters 2006, 89.

TOC Graphic 


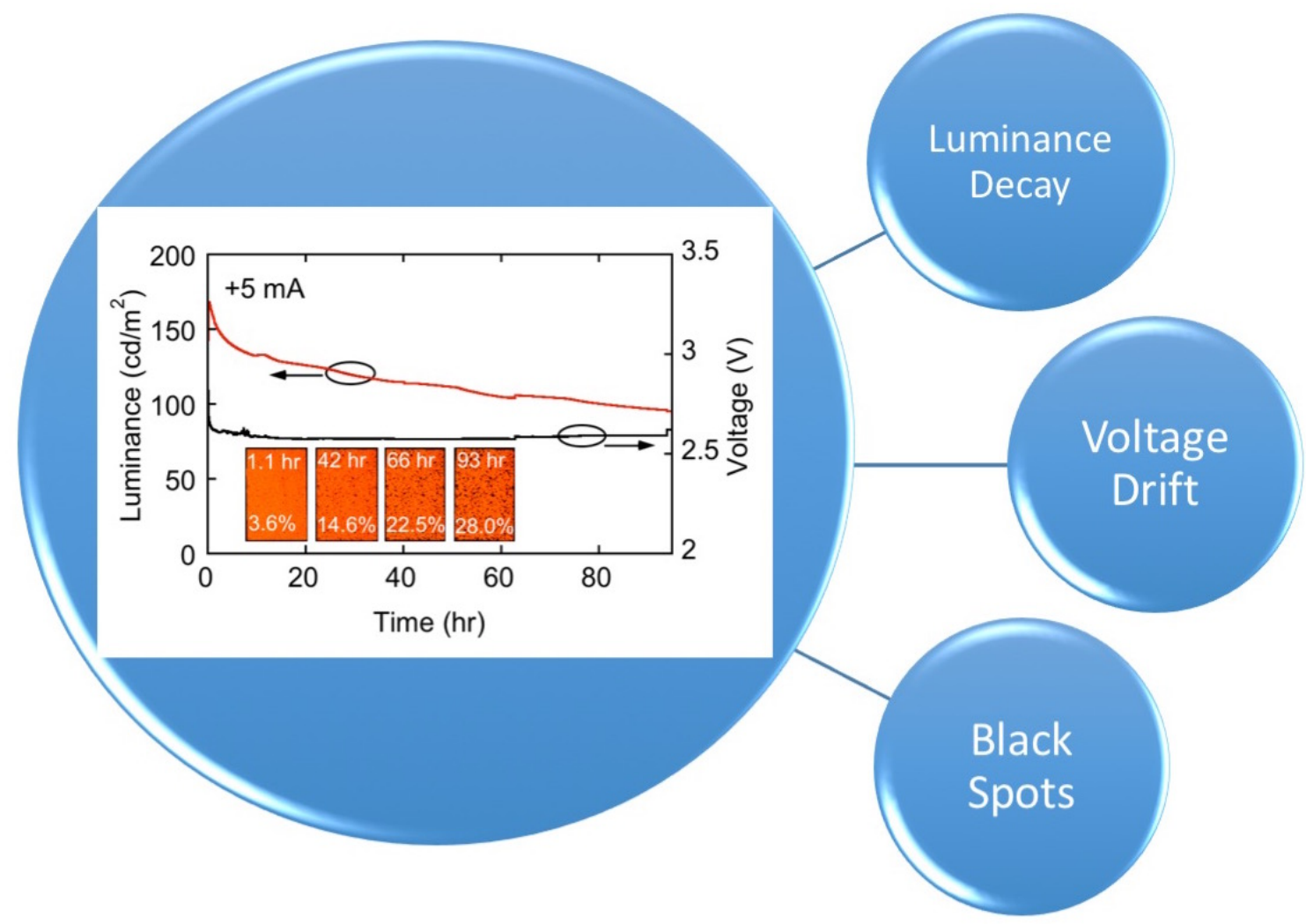

TOC Text:

The stress characteristics of the polymer light-emitting electrochemical cells (PLECs), as measured by luminance decay, voltage drift and black spot formation, have been comprehensively evaluated. Both voltage drift and black spot formation can be effectively suppressed by drastically increasing the electrolyte content. The black spots can also be effectively eliminated by employing silver instead of aluminum as the cathode material. 